\title{
Contribution of Laser Photovaporisation in the Management of Lower Urinary Tract Symptoms Related to Prostatic Tumours: Preliminary Study of 29 Cases at the Saint Camille Hospital of Ouagadougou (Burkina Faso)
}

\author{
Clotaire Alexis Marie Kiemdiba Donega Yaméogo ${ }^{*}$, Bienvenu Ky ${ }^{1}$, \\ Fasnewendé Aristide Kaboré1, Adama Ouattara ${ }^{2}$, Brahima Kirakoya ${ }^{1}$ \\ ${ }^{1}$ Department of Urology, Yalgado Ouédraogo Teaching Hospital, Ouagadougou, Burkina Faso \\ ${ }^{2}$ Department of Urology, Sanon Souro Teaching Hospital, Bobo Dioulasso, Burkina Faso \\ Email: *yameogoclotaire@yahoo.fr
}

How to cite this paper: Yaméogo, C.A.M.K.D., Ky, B., Kaboré, F.A., Ouattara, A. and Kirakoya, B. (2020) Contribution of Laser Photovaporisation in the Management of Lower Urinary Tract Symptoms Related to Prostatic Tumours: Preliminary Study of 29 Cases at the Saint Camille Hospital of Ouagadougou (Burkina Faso). Open Journal of Urology, 10, 1-7.

https://doi.org/10.4236/oju.2020.101001

Received: November 7, 2019

Accepted: December 27, 2019

Published: December 30, 2019

Copyright $\odot 2020$ by author(s) and Scientific Research Publishing Inc. This work is licensed under the Creative Commons Attribution International License (CC BY 4.0).

http://creativecommons.org/licenses/by/4.0/

\begin{abstract}
The treatment of prostatic tumour-related lower urinary tract symptoms (LUTS) uses a varied therapeutic arsenal. In our country, the treatment is dominated by open surgery. Laser treatment is becoming an efficient alternative to trans-urethral prostatic resection or prostatic adenomectomy. We report our experience with the results of Thulium laser photovaporization in the treatment of prostatic tumour-related LUTS. Materials and Methods: A prospective study was conducted between November 2018 and August 2019 at the Saint Camille hospital of Ouagadougou. The inclusion criteria were the presence of LUTS related to a prostatic tumour with an operative indication. Results: 29 patients were treated with Thulium laser prostatic photovaporization. The average age of patients was $72.58 \pm 25.34$ years ( $54-84$ years). The average vaporization duration was $71.24 \pm 21.65$ minutes (15 - 210 minutes) for an average prostatic volume of $80.97 \mathrm{ml}$. The average duration of hospitalization for patients was 1.93 days ( 1 - 5 days). The average bladder sounding duration was 1.68 days ( 1 - 4 days). A capsular perforation, a sphincter lesion and urinary retention after removal of the catheter were the complications. Conclusion: Laser photovaporization is a newly used method at the Saint Camille Hospital. The benefit is the reduction of the risk of bleeding, the short duration of hospital stay and bladder sounding. Photovaporization deserves to be popularized in our daily practices.
\end{abstract}

\section{Keywords}

LUTS, Laser Photovaporization, Prostate, Burkina Faso 


\section{Introduction}

The symptoms of the lower urinary tract associated with a prostatic tumour mainly concern men over the age of 60 [1]. Surgical treatment of lower urinary tract symptoms (LUTS) related to prostate tumours uses a varied therapeutic arsenal. In our context of resource-limited countries, treatment remains predominantly dominated by open-surgery.

Nowadays, the mini-invasive techniques are the most used. Among the surgical techniques, transurethral resection of the prostate (TURP) is still considered as the gold standard for the treatment of benign prostatic hyperplasia, but its main disadvantage is represented by blood loss even if it significantly improves urinary symptoms and urinary flow [2]. Laser treatment is becoming an increasingly used, effective alternative to trans-urethral prostatic resection or prostatic adenomectomy. Several lasers (KTP, Ho: YAG, Thulium ...) and several techniques (enucleation, vaporisation) are currently available, with more and more studies validating reliability, reproducibility, and gain in terms of sounding time and hospitalization, per- and post-operative bleeding [1] [3]. Photoselective vaporization of the prostate is a minimal invasive endoscopic treatment of benign prostatic hyperplasia (BPH) obstruction. It uses the light energy produced by a laser source to destroy and remove urethral obstruction due to BPH. It is useful in patients with bleeding disorders [1].

Laser vaporization of the prostate utilizes the thulium laser section and vaporization capabilities. The material used is a resectoscope, a $1000 \mu$ laser fiber and a $200 \mathrm{~W}$ thulium laser generator. The procedure begins with a section at $50 \mathrm{~W}$ from the bladder neck to veru montanum at 5 and 7 o'clock. First, the median lobe is vaporized at $150 \mathrm{~W}$. The side lobes are then vaporized.

We report our experience with the results of Thulium laser photovaporization in the treatment of prostatic tumour-related LUTS.

\section{Materials and Methods}

A prospective study was conducted between November 2018 and August 2019 within the surgical department of the Saint Camille hospital of Ouagadougou. The inclusion criteria were the presence of a symptomatic prostatic tumour with evidence of surgical management. Our study on the use of laser photovaporization in the surgical management of prostate tumors is the first in west Africa. Were included in this study, patients with benign prostatic hypertrophy with failure of medical treatment based on a blockers or those with a malignant prostate tumor advanced and obstructive who required continuous urinary catheterization. This is our first experience with laser in the surgical management of prostate tumors. It is a new technique and also an expensive one for most of the population.

The procedure was performed under spinal anaesthesia after checking the sterility of the urine. The administration of prophylactic antibiotherapy based on ceftriaxone $2 \mathrm{~g}$ and gentamycin $160 \mathrm{mg}$ was systematic after the induction of 
anesthesia.

The prostatic photovaporization was performed using a Thulium YAG $200 \mathrm{~W}$ laser supplied by a Thulium system. A $30^{\circ} 26-\mathrm{F}$ continuous flow cystoscope was used with the laser set at $80 \mathrm{~W}$ first, $150 \mathrm{~W}$ for vaporization, and $50 \mathrm{~W}$ for coagulation. The fibre is inserted into the continuous flow laser cystoscope with a separate irrigation channel. Isotonic saline serum at room temperature was used for irrigation. A configuration allowing a continuous flow provided sufficient visibility and cooling of the fibre.

The prostate vaporization was performed under vision using laser fibre with a contact scanning technique. The procedure is performed as an TURP, starting with the bladder neck and the lateral lobes, the anterior lobe, and finally the apical part of the prostate [4] [5].

The vesical sounding at the end of the operation was systematic, by the setting up of a double current catheter $22 \mathrm{Fr}$, balloon inflated at $30 \mathrm{cc}$ with continuous irrigation with isotonic saline serum.

The data collected concerned patient characteristics (age, prostate volume), surgical and post-operative data (duration of intervention, complications, duration of sounding, duration of hospitalization).

The data were entered and analysed using the epi info 7 software.

All patients gave informed consent. Patients were assessed in post-operative at 1 month after the intervention.

\section{Results}

\subsection{Characteristics of the Study Population}

A total of 29 patients secondary to benign prostatic hyperplasia (24) and malignant prostate tumor advanced with lymph node and bone metastases (5) were treated by Thulium laser prostatic photo-vaporization during 10 months between November 2018 and August 2019.

The average age of patients was $72.58 \pm 25.34$ years (54 - 84 years). Dysuria, pollakiuria and urinary retention were the reasons for consultation found in all patients. The average prostatic volume was $80.97 \pm 15.72 \mathrm{ml}(30-120 \mathrm{ml})$, of which $75.86 \%$ had a volume less than or equal to $80 \mathrm{ml}$.

\subsection{Post-Operative Management}

The average duration of the interventions was $71.24 \pm 21.65$ minutes with extremes of 15 to 210 minutes. The average prostatic volume was $80.97 \pm 15.72 \mathrm{ml}$. The average duration of hospitalization for patients was 1.93 days ( 1 - 5 days). Hospitalization was less than 48 hours in $86.2 \%$ of patients (Table 1 ).

The average bladder sounding duration was 1.68 days with extremes ranging from one day to 4 days (Table 2). The bladder catheter was removed at one day in $52 \%$ of cases, at two days in $45 \%$ of cases, at three days and four days after in $3 \%$ of cases.

The complications noticed were a capsular perforation; a urethral striated 
sphincter lesion and a urinary retention after removal of the catheter. The postoperative course for the patients was uneventful. No dysuria presented by our patients.

\section{Discussion}

The limits of our study are the small sample size, the patient follow-up time and the absence of uroflowmetry to better objectify the urinary obstruction.

Despite these limits, the following comments or discussions may be made.

The average age of patients in our series was $72.58 \pm 25.34$ years $(54-84$ years). This result was similar to data in the literature showing benign prostatic hypertrophy as a common benign pathology in men over 50 years old and which is responsible for LUTS [6]. These LUTS can have a significant impact on the quality of life and may even be responsible for complications requiring medication or surgery [6]. Bachman [7], Kumar [8], Sandhu [9] found an average of 70.4 years (50 - 90), 72.6 years $(67-95)$ and 70.1 years $(44-92)$.

In our study, the average duration of the interventions was $71.24 \pm 21.65 \mathrm{mi}$ nutes with extremes of 15 to 210 minutes. The average prostatic volume was $80.97 \pm 15.72 \mathrm{ml}$. The duration of the procedure depends on the prostatic volume, the laser's power and the operator's experience. Bachman [7], noted an average intervention time of 54.5 minutes for an average prostatic volume of $52.2 \mathrm{ml}$, Kumar [8] 33.5 minutes for a prostatic volume of $53.2 \mathrm{ml}$ and Sandhu [9] 123 minutes for a prostatic volume of $101 \mathrm{ml}$.

The average operative times varied between 30 and 140 minutes depending on the series [10]. Although the technique was considered by some people to be slower and laborious than a trans-urethral resection of the classical prostate, it did not identify any significant difference between the operative duration of laser photovaporization and that of trans-urethral resection of the prostate [11].

Table 1. Duration of hospitalization.

\begin{tabular}{ccc}
\hline Duration & Frequency (n) & Percentage (\%) \\
\hline $24 \mathrm{H}$ & 10 & 34.4 \\
$48 \mathrm{H}$ & 15 & 51.8 \\
$72 \mathrm{H}$ & 2 & 6.9 \\
$120 \mathrm{H}$ & 2 & 6.9 \\
Total & 29 & 100 \\
\hline
\end{tabular}

Table 2. Bladder sounding duration.

\begin{tabular}{ccc}
\hline Duration & Frequency (n) & Percentage (\%) \\
\hline $24 \mathrm{H}$ & 14 & 48.3 \\
$48 \mathrm{H}$ & 12 & 41.4 \\
$72 \mathrm{H}$ & 1 & 3.4 \\
$96 \mathrm{H}$ & 2 & 6.9 \\
Total & 29 & 100 \\
\hline
\end{tabular}


Concerning the duration of hospitalization and vesical sounding, in the literature the tendency is rather towards vesical and short-term hospital stay [12].

Bouchier-Hayes, 2006 [13] noted an average duration of 12 hour-bladder sounding with a hospital stay of one day. Heinrich, 2007 [14] and Ruszat, 2007

[15] respectively found an average bladder sounding duration of 1.4 days and 1.8 days with a hospital stay of 3.6 days and 3.8 days.

The average duration of hospitalization for patients was 1.93 days ( 1 - 5 days).

In our series, the bladder catheter was removed at one day in $52 \%$ of the cases, at two days in $45 \%$ of the cases, and at three days and four days in $3 \%$ of cases after sounding.

Our results can be explained by the high prostatic volume, the surgical complications such as: capsular perforation, urinary retention and sphincter lesion; and our first year of experience. Kumar S.M. found a capsular perforation [8]. Other complications have been noted by other authors. Delayed hematuria, urgenturia, urethral stricture were reported by Maleck and colleagues [16].

The laser thulium allows in addition to the vaporization to perform a prostatic enucleation. This prostatic enucleation allows a gain in time. This makes possible the surgery of prostatic tumors with large volume [9] [17].

\section{Conclusions}

Laser photovaporization is a new method used in the surgical department of the Saint Camille hospital. This alternative has completely changed the management of symptomatic obstructive prostatic pathologies. The major benefit of photovaporization is the reduction of hemorrhagic risk, the short duration of hospital stay and bladder catheter use.

The achievement of good results and its low morbidity support its importance in the management of prostatic tumours. In our country, its popularization deserves to be encouraged.

\section{Consent}

Consents of the patients were obtained before publication of this article.

\section{Conflicts of Interest}

The authors declare no conflicts of interest regarding the publication of this paper.

\section{References}

[1] Bruyère, F. (2011) La photovaporisation laser de la prostate. Progrès en Urologie, 21, 808-810. https://doi.org/10.1016/j.purol.2011.08.026

[2] Lebdai, S. and Descazeaud, A. (2014) Prise en charge des symptômes du bas appareil urinaire liés à l'hypertrophie bénigne de la prostate. Progrès en Urologie, 24, 929-933. https://doi.org/10.1016/j.purol.2014.07.010

[3] Fourmarier, M., et al. (2009) Revue de la littérature sur l'utilisation des lasers pour 
le traitement de l'HBP symptomatique. Progrès en Urologie, 19, 153-157. https://doi.org/10.1016/j.purol.2008.10.017

[4] Elshal, A.M. and Elhilali, M.M. (2018) Holmium Laser Therapy of the Prostate. In: Smith, A.D., et al., Eds., Smith's Textbook of Endourology, Fourth Edition, Volume 1, John Wiley \& Sons Ltd., Hoboken, 1681-1692. https://doi.org/10.1002/9781119245193.ch145

[5] Misraïa, V., Rouprêtb, M., Guillotreaua, J., Bordiera, B. and Bruyère, F. (2013) Traitement de l'hyperplasie bénigne de prostate par photovaporisation au laser Greenlight: Analyse de la littérature. Progrès en Urologie, 23, 77-87. https://doi.org/10.1016/j.purol.2012.10.013

[6] Bruyere, F. and Traxer, O. (2007) Photovaporisation de la prostate par laser KTP (potassium-titanyl-phosphate). Progrès en Urologie, 17, 783-788. https://doi.org/10.1016/S1166-7087(07)92292-7

[7] Bachmann, A., Ruszatr, W.S., Reich, O., Seiferth, H., Muller, A., et al. (2005) Photoselective Vaporization of the Prostate: The Basel Experience after 108 Procedures. European Urology, 47, 798-804. https://doi.org/10.1016/j.eururo.2005.02.003

[8] Kumar, S.M. (2005) Photoselective Vaporization of the Prostate: A Volume Reduction Analysis in Patients with Lower Urinary Tract Symptoms Secondary to Benign Prostatic Hyperplasia and Carcinoma of the Prostate. Journal of Urology, 173, 511-513. https://doi.org/10.1097/01.ju.0000150099.31289.d7

[9] Sandhu, J.S., Ng, C., Vanderbrink, B.A., Egan, C., Kaplan, S.A. and Te, A.E. (2004) High-Power Potassium-Titanyl-Phosphate Photoselective Laser Vaporization of Prostate for Treatment of Benign Prostatic Hyperplasia in Men with Large Prostates. Urology, 64, 1155-1159. https://doi.org/10.1016/j.urology.2004.07.018

[10] Naspro, R., Bachmann, A., Gilling, P., Kuntz, R., Madersbacher, S., Montorsi, F., et al. (2009) A Review of the Recent Evidence (2006-2008) for 532-nm Photoselective Laser Vaporisation and Holmium Laser Enucleation of the Prostate. European Urology, 55, 1345-1357. https://doi.org/10.1016/j.eururo.2009.03.070

[11] Lourenco, T., Armstrong, N., N’Dow, J., Nabi, G., Deverill, M. and Pickard, R. (2008) Systematic Review and Economic Modelling of Effectiveness and Cost Utility of Surgical Treatments for Men with Benign Prostatic Enlargement. Health Technology Assessment, 12, 1-146, 169-515. https://doi.org/10.3310/hta12350

[12] Barry Delongchamps, N., et al. (2012) Traitement chirurgical de l'hyperplasie bénigne de la prostate par laser: Revue de littérature du CTMH de l'AFU. Progrès en Urologie, 22, 80-86. https://doi.org/10.1016/j.purol.2011.07.008

[13] Bouchier-Hayes, D.M., Anderson, P., Van Appledorn, S., Bugeja, P. and Costello, A.J. (2006) KTP Laser versus Transurethral Resection: Early Results of a Randomized Trial. Journal of Endourology, 20, 580-585. https://doi.org/10.1089/end.2006.20.580

[14] Heinrich, E., Schiefelbein, F. and Schoen, G. (2007) Technique and Short-Term Outcome of Green Light Laser (KTP, 80 W) Vaporisation of the Prostate. European Urology, 52, 1632-1637. https://doi.org/10.1016/j.eururo.2007.07.033

[15] Ruszat, R., Wyler, S., Forster, T., Reich, O., Stief, C.G., Gasser, T.C., et al. (2007) Safety and Effectiveness of Photoselective Vaporization of the Prostate (PVP) in Patients on Ongoing Oral Anticoagulation. European Urology, 51, 1031-1041. https://doi.org/10.1016/j.eururo.2006.08.006

[16] Malek, R.S., Kuntzman, R.S. and Barrett, D.M. (2005) Photoselective Potassium-Titanyl-Phosphate Laser Vaporization of the Benign Obstructive Prostate: 
Observations on Long-Term Outcomes. Journal of Urology, 174, 1344-1348. https://doi.org/10.1097/01.ju.0000173913.41401.67

[17] Hajebrahimi, S., Mahboub-Ahari, A., Sadeghi-Ghyassi, F., Mostafaie, A. and Yousefi, M. (2011) Holmium Laser Prostate Enucleation (HOLEP) versus Trans-Urethral Resection of Prostate (TURP) in Treatment of Symptomatic Prostatic Enlargement: A Health Technology Assessment. Journal of Lasers in Medical Sciences, 2, 36-42. 